\title{
New horizons in EU-Japan security cooperation
}

\author{
Emil J. Kirchner ${ }^{1}$ (D) Han Dorussen ${ }^{1}$ \\ Received: 24 July 2019 /Revised: 11 June 2020 / Accepted: 7 July 2020 / \\ Published online: 16 July 2020 \\ (C) Springer-Verlag GmbH Germany, part of Springer Nature 2020
}

\begin{abstract}
Alongside the EU-Japan Economic Partnership Agreement (EPA), a Strategic Partnership Agreement (SPA) between the EU and Japan entered into force in 2019. Whereas the EPA enshrines the existing interconnectedness between the Japanese and European economies, the SPA remains more aspirational. With an emphasis on shared norms and values and recognising an increasingly hostile external environment, the EU and Japan are seeking to deepen and broaden their security cooperation. For the period 19902017, EU-Japan security cooperation is mapped for a broad range of security domains. During this period, cooperation has increased notably in domains such as economic security, cyber-security and civil protection. In other areas, such as military, regional, energy and human security as well as terrorism, the scope of cooperation lags behind. Looking forward, the SPA not only reflects a renewed interest and level of ambition in the EU and Japan but also provides them with a platform to extend security cooperation to address their global and regional challenges.
\end{abstract}

Subject EU external relations, Japan, security cooperation, Strategic Partnership Agreement, threat perceptions, policy convergence

\section{Introduction}

The Economic Partnership Agreement (EPA) and the Strategic Partnership Agreement (SPA) are recent milestones in the economic and political relations between the EU and

This article resulted from a research project funded by the European Union under ERASMUS+/Jean Monnet Activities (Grant no. 574634-EPP-1-2016-1-UK-EPPJMO-PROJECT). Since it brings together the findings presented in the individual chapters Kirchner and Dorussen (2019), we specially thank all contributors. We remain fully responsible for all interpretations of facts and the overall analysis.

Han Dorussen

hdorus@essex.ac.uk

Emil J. Kirchner

emil@essex.ac.uk

1 Department of Government, University of Essex, Wivenhoe Park, Colchester, Essex CO7 9NX, UK 
Japan. In particular, the EPA demonstrates the dramatic changes in how Japan is viewed across Europe: whereas in the 1980s, the EU saw Japan primarily as a competitor and a challenger, it is now seen as a major economic partner, occupying sixth place in EU trade volume. The EU Global Strategy (EUGS) recognises that threats to the EU's or Japan's position in the global economy are likely to have serious repercussions for their growth, their prosperity and ultimately also their security.

There is a direct connection between European prosperity and Asian security. In light of the economic weight that Asia represents for the EU-and vice versa - peace and stability in Asia are a prerequisite for our prosperity. We will deepen economic diplomacy and scale up our security role in Asia. (European Union 2016: 37)

The EU and Japan have steadily worked to develop their political relations. The Joint Declaration of 1991, the Action Plan of 2001 and the introduction of a Strategic Partnership in 2003, enhanced in 2019, mark the evolution of the relationship (European Community 1991; European Commission 2001; European Council 2012). They also reflect the increased relevance of the EU as a foreign policy actor and, as we will argue later, a path towards meaningful EU-Japan security cooperation. ${ }^{1}$

Between 1990 and 2017, the EU and Japan have explored cooperation in a number of security domains, encompassing both traditional and non-traditional security sectors, but actual collaboration achieved over time has been uneven. Hence, a first objective is to systematically assess the extent and relevance of EU-Japan security cooperation across security domains over this period in order to identify main drivers and barriers to cooperation. Our analysis provides a comparative perspective on EU-Japan security relations distinguishing between European versus Japanese perspectives regarding 12 different security domains for three different time periods. The comparative analysis allows for an assessment of potential future collaboration in terms of unrealised potential but also in response to international developments.

Following Most and Starr (1989), opportunities and constraints can be seen as structuring security cooperation. Perceived threats in a particular security domain create a demand for collaboration; for example, the North Korean nuclear and missile programmes have heightened concerns about proliferation and regional tensions. International terrorism, climate change and cyber-attacks, and most recently pandemics such as Covid-19 have also received increased attention in EU-Japan security dialogues (EUobserver 2020). Yet heightened attention does not always lead to more collaboration. EU and Japanese assessments of threat level may vary; for example, uncontrolled immigration is high on the EU security agenda while it is a minor concern for Japan. Moreover, the EU and Japan have developed different, and occasionally incompatible, policy responses in particular security domains. These regularly reflect structural differences; for example, Japan is a state while the EU ultimately relies on its member states in shaping its security policies. Therefore, we propose lack of

\footnotetext{
${ }^{1}$ The focus of our analysis is on EU-Japan security relations, rather than on the security relations of individual EU's member states with Japan, though some attention will be devoted to the latter in the section on Internal Factors.
} 
convergence in threat perception and policy response in a particular security sector as the major constraint on collaboration (see also de Prado Yepes 2017).

While initially focusing on the impact of internal factors and shared values on EUJapan security cooperation, we remain cognisant that these effects may be to a large extent checked or overridden by external influences, such as changes in the geopolitical landscape in Asia and Europe, the rise of China and Chinese assertive maritime behaviour, Russian hybrid security threats and Trump's 'America First' policy. The role of the US is particularly important since it provides critical defence protection to Japan and is a pivotal ally of nearly all EU member states via shared NATO membership. Standing defence arrangements have not only affected EU attempts to develop an autonomous common security and defence policy (CSDP) but they have also by some measure limited EUJapan security cooperation. During the Cold War, Europe and - even more so-Japan relied on the United States as their main security guarantor and consequently they saw each other primarily as 'a friend of a friend'. Since 1990, however, Japan and Europe have sought — and to some extent have been compelled — to redefine their security strategies, a process that may have been hastened along by President Trump. As a result, Japan and Europe, and in particular the EU, have not only pursued more independent voices but they also increasingly appreciate each other as 'old friends'.

The next section provides a systematic and comparative analysis EU-Japan security relations map threat perceptions and policy responses across a broad range of security domains to assess EU-Japan security cooperation for the period 1990-2017. Relying in part on the results from an expert survey, it provides an assessment of trends and patterns over time as well as across policy dimensions. It comprises information on levels of threat perception by the EU and Japan, corresponding levels of convergence in threat perception and policy response by both partners, and the levels of bilateral and multilateral cooperation achieved between the two partners. The general analysis is followed by a section identifying factors - both internal and external to the EU and Japan - that have conditioned joint cooperation in specific security sectors. The subsequent section discusses the future of EU-Japan security cooperation, assessing recent changes in the geopolitical landscape in Asia and Europe and the possible impact of President Trump's 'America First' policy. The concluding section explores the likely impact of the SPA across various security sectors and new horizons of EU-Japan security cooperation.

\section{Mapping EU-Japan security cooperation from 1990 until 2017}

The overriding objective of security cooperation is to counter perceived threats: allies coordinate military operations in response to possible attacks, or they work together in cutting greenhouse gas emissions to tackle climate change. Hence, the first guiding principle of our investigation is that perceived insecurity creates a demand, or opportunity (Most and Starr 1989), for cooperation to more effectively counter threats in a particular area. The second guiding principle is that differences in threat perception or policy approaches are main barriers, or constraints, to actual cooperation. Similar and compatible policies in a particular security domain make it easier for partners to cooperate, while cooperation will be more difficult where they diverge in their approaches. To better understand variation in security cooperation in different policy 
domains, our theoretical framework therefore focuses on convergence in threat perception and convergence on policy response to such threats in specific policy domains.

To provide a systematic and comparative analysis of collaboration in EU-Japan security relations, the research proceeded through a number of steps. The first step entailed an assessment of official EU and Japanese threat perceptions across 12 different security sectors over a nearly 30 -year time period. These assessments are scaled as low, medium or high. The second step involved a scaled assessment-again classified as high, low or medium - of the degrees of convergence or divergence in threat perceptions and policy response thereof between the two partners. The third step evaluates whether convergence in threat perception and policy response correlated with levels of cooperation between the two partners. And to the extent they do not, it explores whether internal (to the EU or Japan) or external (US, China or Russia) influences to EU-Japan security relations across the 12 different sectors could help to explain variations.

Empirically, the assessment of threat perception, policy response and cooperation is based on an expert survey of European and Japanese researchers. Scholars were approached based on their high level of expertise and experience in a particular security area. They were identified in a number of ways, such as a review of extant literature, online searches (e.g. Google and LinkedIn) but also previous collaboration and recommendations. For each security domain, the analysis relies on European as well as Japanese scholars. $^{2}$ First, the Japanese and European experts worked together in preparing a research paper covering a specific security domain (Kirchner and Dorussen 2019). The papers were discussed in three workshops held in Berlin, Kobe and Brussels in 2017 and 2018. Subsequently, the expert survey collated parallel assessments completed independently by the European and Japanese scholars for their specific area of expertise. Importantly, the expert survey completed a lengthy process in which the scholars examined and deliberated EU-Japan security relations, and the survey thus mainly collated the key insights for a particular security domain. The approach allowed us to identify not only difference in threat perception and policy response between the EU and Japanese government but possibly also divergent perceptions by European and Japanese experts.

The main comparison is however across policy domains. The analysis focused on 12 security areas, namely, regional security, military security, (non)proliferation, terrorism, organised crime, climate security, energy security, human security, civil protection, cyber-security, economic security and (im)migration. Importantly, these include both traditional and non-traditional conceptions of security with at least a minimum level of salience in either Japan or the EU. Finally, the mapping exercise covers three periods in EU-Japan security cooperation: 1991-2000, 2001-2010 and 2011-2017. These time periods are not only roughly comparable but they also reflect meaningful stages in the development of EU-Japan security cooperation. In 1991, the Joint Declaration on Relations between the EC and its Member States and Japan initiated regular policy dialogues. The 2001 Action Plan for EU-Japan Cooperation marks the start of the second period in which security dialogues became a distinct feature of relation. The

\footnotetext{
${ }^{2}$ The experts on EU security policies are based across Europe, specifically, Hamburg University, Heidelberg University, Italian Institute of International Affairs, Leuven University, Stiftung Wissenschaft und Politik, Tübingen University, University of Essex, University of Luxembourg, University of Maastricht, University of St. Louis (USA) and University of Warwick. Japanese experts are based at Japan Society for Security Crisis Management, Keio University, Kobe University, National Institute for Defence Studies, Setsunan University, Sophia University and the University of Sacred Hearts.
} 
establishment of the EU-Japan High-Level Group in 2011 provided new impetus to deepen political, economic and security relations that led in 2013 to the start of negotiations on the EPA and SPA, which were both agreed in principle in 2017.

To further ensure compatibility over time and across security domains, a simple classification of perceived threat levels, convergence and cooperation as low, medium or high is applied. Security threats are perceived as high if, in official statements, developments in an issue area are regarded as main or significant threats with a high propensity to affect the peace and stability of the polity. Importantly, the experts were asked to focus on - and identify - official government evaluations. Medium-level threats are identified as such in official statements but without necessarily involving a high propensity to affect the peace and stability of the polity. Threat levels are low in a particular area if developments have received little, if any, attention as threats in official documents. For each dimension, an EU expert was asked to evaluate the threat level for the EU, while a Japanese expert was asked the same for Japan. As an indication for overall threat, the lower threat level (of either the EU or Japan) is used. By applying the weakest-link assumption (Russett and Oneal 2001), it is presumed that the partner with the lower security concerns set opportunities for cooperation; in other words, threat perception is understood as identifying a demand or need for cooperation. We recognise that threats can emanate for a number of different sources, but rather than trying to explain the perceived levels of threat, our analysis directs attention to the implications of increased salience of threats (and convergence of threat perception) on the development of EU-Japan security relations.

Figure 1 summarises levels of threat perceptions for the 12 policy areas. Clearly, both the EU and Japan have increasingly identified more areas with high threat levels. Between 1991 and 2000, the EU as well as Japan considered threats as high in only a small minority of policy areas, while threats were seen as low level in three (EU) and

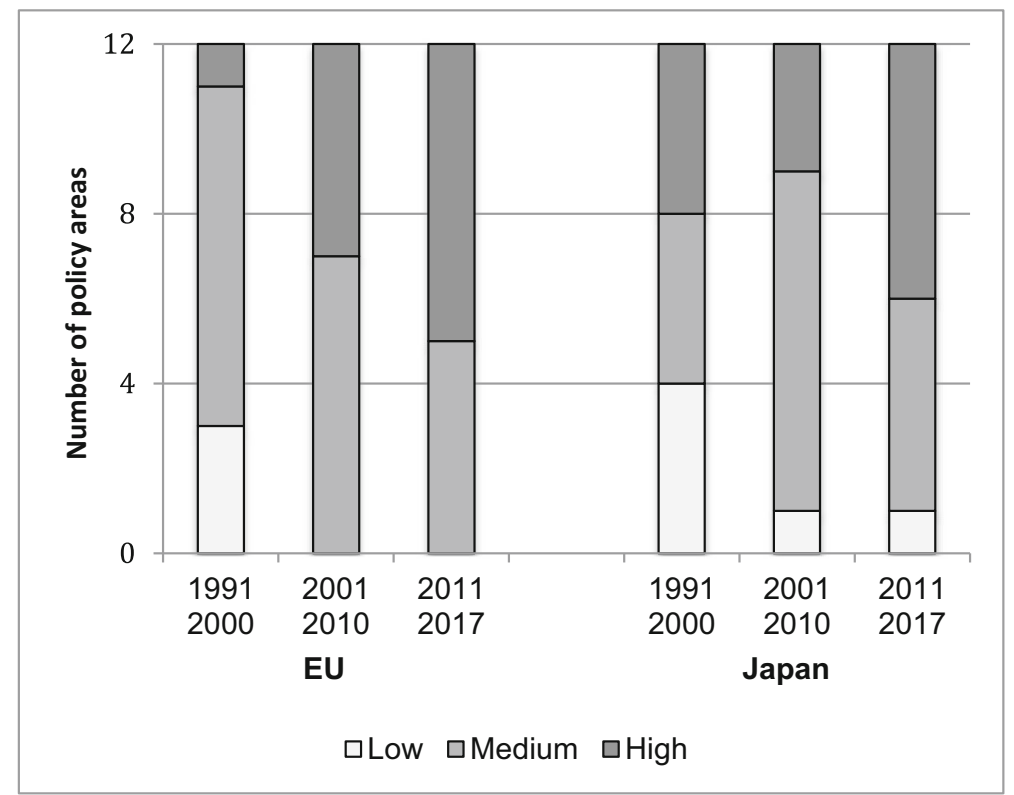

Fig. 1 EU and Japan threat perception. Source: Kirchner and Dorussen 2019, p. 206. 
four (Japan) areas, respectively. In the last period (2011-2017), threats were seen as at least medium level in nearly all policy areas with high threat levels in the majority of policy areas. These patterns apply to both the EU and Japan, suggesting that both parties have an increasing demand for cooperation on security matters. There is, however, a clear difference in what are seen as the primary sources of threat. On the EU side, Russia, political instability in the Middle East and Jihadism are most commonly mentioned across policy areas. The main sources of threat for Japan are North Korea and China.

Convergence is assessed by the extent to which uniform positions exist between the EU and Japan. Convergence applies both to the perception of threat as well as to relevant policy response in a particular security dimension. Convergence is high if both partners agree on the seriousness of a threat and have a high degree of overlap in domestic response. Medium convergence indicates either disagreement on the seriousness of threats or significant variation or difference in their policy response. Low convergence indicates variation in threat perception as well as policy response.

Cooperation is measured by means of the presence of joint actions and formal agreements in a particular security dimension. High levels of cooperation require that both partners actively and frequently engage in joint actions including the involvement of personnel and resources. Cooperation is judged as medium if joint actions are infrequent but there is a common understanding and recognition of the need to address problems together. At medium levels of cooperation, there is still evidence of a willingness to commit personnel and resources but there is also recognition of barriers to more regular joint action. At low levels of cooperation, joint actions are sporadic, leaving any 'cooperation' to take place predominantly at the level of discourse or intention rather than practice.

Since levels of convergence and cooperation were also assessed separately for the EU and Japan, Fig. 2 applies the weakest-link assumption; this is a conservative approach that in effect uses the lowest score as the overall assessment. Over time, EU and Japanese responses have become somewhat more compatible and cooperation has increased. The number of policy areas with medium convergence has steadily grown from two (in 1990-2000) to four (2001-2010) to six (2011-2017). However, no dimension has high levels of convergence even in the most recent period. At the same time, the number of areas with low levels of cooperation has decreased-from ten in the second period to eight in the last period. Yet even in the last period, economic security remains the only dimension with a high level of cooperation. A comparison of Figs. 1 and 2 suggests that levels of cooperation lag behind levels of convergence that in turn lag behind the heightened levels of threat perception.

These general patterns, however, hide some interesting variations that apply to specific security domains. Figure 3 provides line graphs for each of the 12 security domains charting the patterns of threat perception, policy convergence and cooperation. Here, the weakest-link assumption has been applied to threat perceptions, while the evaluations of convergence and cooperation have been averaged, resulting in a fivepoint scale: low, low/medium, medium, medium/high and high.

The perceived security threat has remained constant at medium level across the three periods in two policy areas: military and human security. Threat perception has increased to high levels in the areas of regional security, (non)proliferation and cyber-security while increasing to medium in organized crime, climate security, energy 


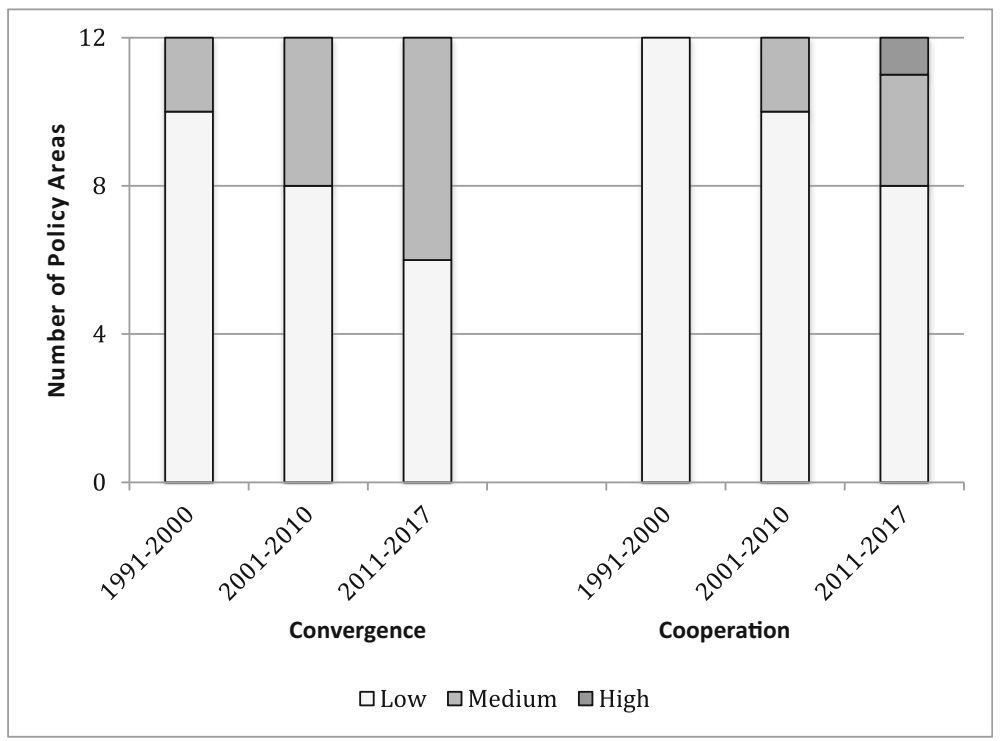

Fig. 2 Policy convergence and EU-Japan cooperation. Convergence and cooperation: weakest-link assumption. Source: Kirchner and Dorussen 2019, p. 208.

security, civil protection, (im)migration and economic security. It has decreased to low for terrorism, reflecting the low level of Japanese concerns, but the EU and Japan diverge markedly in their perception of the threat of terrorism: whereas it is low for Japan, it is high for the EU.

In the latter periods, policy convergence exceeds the level of threat perception only in the economic security dimension and terrorism. Economic security is a further outlier in the sense that only in this area, the level of cooperation is higher than the level of convergence and threat perception. Also in civil protection, the level of cooperation exceeds the extent of policy convergence in the final period (2010-2017). In (non)proliferation, climate security, cybersecurity and (im)migration, levels of policy convergence and actual cooperation closely align over the three periods. However, in the final period, the level of cooperation remains lower than the level of policy convergence in five security areas, namely, military security, regional security, terrorism, energy security and human security. Arguably-since threat perception is best understood as the need (or demand) for cooperation and policy convergence as a constraint or limit to supply - there is a joint demand for more cooperation in eight (of the 12) security dimensions and an unrealised potential for cooperation in five. Of these five, in three policy areas (military, regional and human security), actual cooperation falls below threats perception as well as policy convergence.

The basic assumption that levels of threat perception are linked to levels of cooperation does not appear to hold for all security areas, including salient sectors such as regional and military security. Moreover, in the five areas where the level of cooperation falls below the level of convergence, neither can policy constraints fully explain lack of cooperation. What could then explain these deviations? Next, we discuss a number of intervening factors as possible obstacles to cooperation. 

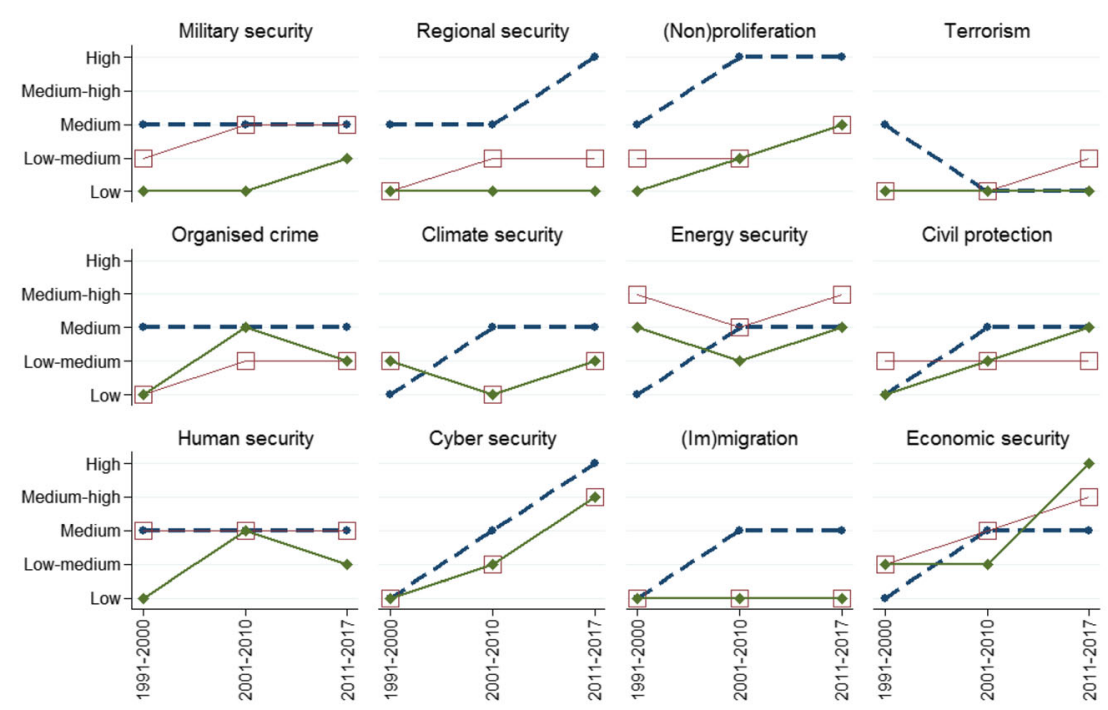

Cyber security

(Im)migration

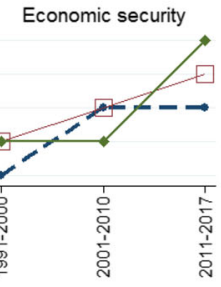

ニーーー- Threat $\square$ Convergence $\square$ Cooperation

Fig. 3 EU-Japan security relations: threat perception, policy convergence and cooperation. Source: Kirchner and Dorussen 2019, p. 209.

\section{Obstacles to EU-Japan security cooperation}

A number of intervening factors can be identified that affect correlations between levels of threat perception and levels of cooperation, as well as between levels of convergence and levels of cooperation. Some of these can be considered as internal factors, that is, arising within the EU or Japan or between the two partners, and some as external where so-called third actors or international crises are involved.

\section{Internal factors}

Arguably, the main internal factors are developments in the field of EU common security and defence, domestic defence policy reforms in Japan, and bilateral relations between EU member states and Japan. The EU has only slowly developed its CSDP and still only has a very limited autonomous military capacity. The CSDP has existed for a considerable period in the shadow of the EU economic policy development. In 1988, France and the UK endorsed the idea of EU military capacity in the St Malo Declaration, but only in 1999 did it receive support from the European Council. Yet the 1997 Amsterdam Treaty established the position of High Representative for the Common Foreign and Security Policy, building on the 1992 Maastricht Treaty, which had introduced the European Security and Defence Policy. Only by 2003 did the EU introduce practical steps such as the first civilian EU police mission to Bosnia, the first EU military operation, known as Concordia, deployed to the former Yugoslav Republic of Macedonia, and the publication of the European Security Strategy (European 
Council 2003). A further consolidation of CSDP efforts took place with the 2007 Lisbon Treaty that introduced a range of defence-relevant clauses, including Permanent Structured Cooperation (PESCO), mutual assistance, solidarity commitment and the establishment of the European External Action Service.

Prior to the implementation of the Lisbon Treaty, the EU thus lacked clear institutional mechanisms and policies in the field of security and defence. Still some EUJapan security cooperation existed even prior to the Lisbon Treaty, involving, for example, non-proliferation, climate and energy security, all sponsored by UN treaties or protocols. In addition, the need to respond to natural disasters facilitated some cooperation in the sector of civil protection, an area where the EU had begun to develop its own mechanisms (Kirchner et al. 2014). The EU also had sufficient authority to establish some cooperation in economic security prior to the Lisbon Treaty. The security provisions of the Lisbon Treaty increased the scope of security cooperation after 2010, but the EU lacks capacity to be an effective partner in addressing the militarised threats Japan faces in its region which could explain lagging cooperation in the regional and military security.

Particular interests of EU member states can impede, but on occasion also promote, EU-Japan level security cooperation. For example, both France and the UK have defence cooperation agreements with Japan, involving the development of military equipment (Ueta 2013, 2). Equally, Germany and Japan have extensive economic and political ties and share interests on the basis of their strongly export-oriented economies. Given the hybrid nature or co-existence of European and national security policy, member states are bound to play an important role in EU-Japan level security cooperation. However, in several instances, the EU has demonstrated that it constitutes a security actor in its own right when dealing with Japan. Examples are the anti-piracy operation in the Gulf of Aden, the climate change negotiations and counter-terrorism measures.

The Japanese government also has to deal with important constraints on its security policies. The security reform programmes are decisive for Japan's ability to engage in security cooperation. In particular, the outcome of attempts by the Japanese government to change Article 9 of the constitution will affect the room for EU-Japan security cooperation, especially when such cooperation involves the deployment of military resources abroad. Article 9 is regularly mentioned as an impediment to Japan's ability to cooperate in areas such as human security (Vosse 2018), military security (Akutsu and Duke 2019) and counter-terrorism (Bossong and Bothe 2019).

\section{External factors}

Since 2013, important changes in the geopolitical context have taken place in Europe as well as Asia that are likely to shape how 'third countries' impact on EU-Japan security relations. In the European context, the Russian annexation of the Crimea in 2014 and mounting threats since then directed at other East European states have raised the spectre of a prolonged conflict with Russia. Chinese maritime assertiveness in the China seas, involving the Chinese declaration of an Air Defence Identification Zone in the East China Sea in 2013, and the North Korean missile launches, including trajectories over Japanese territory, have heightened tensions and the possibility of military conflict. 
Clearly, EU-Japan security cooperation does not exist in isolation but takes place within broader and often longer-established security networks, forcing both sides to take the interests of so-called third parties into consideration. For the EU and even more for Japan, the US has been crucial in shaping and sustaining these networks. Most of the EU member states are part of NATO and embrace a broader defence arrangement with the United States. In contrast, Japan finds itself in a bilateral defence relationship via the US-Japan Security Treaty of 1952, which continues to bind Tokyo to the foreign policy decisions of Washington (Gilson 2016). An example is the issue of nonproliferation, where Japan's position of simultaneously promoting nuclear disarmament and relying on extended nuclear deterrence by the United States has sometimes invited criticism both within the country as well as from abroad (Casarini and Tsuruoka 2019).

North Korea's escalating nuclear threats and assertive Chinese maritime actions in the East and South China Sea affect the security of both the United States and-more directly-Japan. The perceived need for US protection is to some extent reinforced by the Japanese image of the EU as being either unable militarily or unwilling politically to be a genuine security provider. It is of course true that the EU is primarily an economic rather than a military entity, such as NATO, and is consequently limited in terms of providing military assistance. The reference to unwillingness relates to the socalled neutral role the EU has adopted in the maritime conflict between China and Japan, especially over the territorial claims of the Senkaku/Diaoyu islands. The perceived lack of EU military clout and its neutral political stance amount to what Tsuruoka (2008) coins the 'expectation gap' in Japan-EU relations. These issues go to the heart of EU-Japan regional and military security cooperation and are reflected in the low levels of cooperation regional and military security.

The geopolitical changes in Europe and Asia have been further exacerbated by uncertainties about the implications of President Trump's 'America First' policy, for example, with regard to NATO, global trade and climate change. As many of these areas are in flux, their impact on EU-Japan security cooperation remains indeterminate. The next section examines the steps which the EU and Japan have taken either separately or jointly since 2016 in response to the on-going geopolitical changes and to uncertainties emanating from the Trump Presidency, and how these steps might affect the future of EU-Japan security cooperation.

\section{The future of EU-Japan security cooperation}

Both Japan and the EU are enhancing their respective security and defence capacities. A revision of Article 9 of the Japanese constitution, sought by Prime Minister Abe, would create more room to manoeuvre in the Japanese defence posture. Japan is already boosting its defence spending, which in 2017 represented $0.9 \%$ of GDP, compared with an average of $1.3 \%$ among European members of NATO and $3.1 \%$ in America (Economist 2018). Japan has also upgraded its Self Defence Forces through the creation of a central command station in April 2018, which will control Japan's five (previously separate) regional armies and a new amphibious brigade (Gale and Tsuneoka 2018). Whereas revising Article 9 would undoubtedly strengthen Japan's capacity in human security missions, there is also a risk that it would harden policy positions of China and North Korea and could thus exacerbate regional security threats. 
Events since 2014 have also encouraged the EU to reinforce the Lisbon provisions regarding security and defence, for example, the introduction of the EUGS, the EU Military Planning and Conduct Capability, a European Defence Fund to support EU defence research and capability development, and an expressed commitment to enhance PESCO activities. The EUGS makes a direct connection between European prosperity and Asian security, and pledges to deepen economic diplomacy and scale up the EU's security role in Asia. Japan, the Republic of Korea and Indonesia are specifically mentioned in this context (European Union 2016). Support for non-proliferation efforts on the Korean peninsula and upholding the freedom of navigation and respect for international law are seen as priorities. The 2018 EU document on 'Enhanced EU Security Cooperation in and with Asia' re-emphasises these aims (European Council 2018).

Moreover, rising costs for defence equipment, especially those involving new technologies, such as Artificial Intelligence and quantum computing, exert pressure for further cooperation. Already, discussions have started on how to involve Japan in defence research and capability development projects of the European Defence Fund (Tsuruoka and Fiott 2020). These efforts could be strengthened by the EU and Japan Partnership on Sustainable Connectivity and Quality Infrastructure (EEAS 2019) that was established in September 2019. It calls for transparent procurement practices, the ensuring of debt sustainability and high standards of economic, fiscal, financial, social and environmental sustainability. This agreement could also be seen as a riposte to China's growing assertiveness in regional and global order-shaping (Geeraerts 2019).

Further EU-Japan security cooperation might also be expected from Japanese attempts to strengthen its peacekeeping mandate, which could pave the way for further Japanese participation in EU civilian and military missions in places like Africa. Already Japan contributes to the EU anti-piracy naval operation (EU NAVFOROperation Atalanta) in the Gulf of Aden (Vosse 2018). Both the EU and Japan share a common interest in keeping the sea lines of communication open. Japan has also undertaken supportive activities in other civilian EU missions in Africa, which is in line with its desire for greater involvement in international peacekeeping efforts.

Against these potential positive developments in EU-Japan security cooperation, there are also potential obstacles to such a development. These might arise from internal challenges, such as the possibility of Prime Minister Abe not being able to obtain sufficient public consensus for replacing Article 9 or the EU being unable to cope adequately with the largely unknown impact of Brexit. Given the large share of Japanese trade and investment in the UK, the existing level of bilateral military cooperation, and the (occasional) contribution British navy ships make to secure the freedom of navigation in the East and South China Sea, Brexit is bound to affect EU-Japan security relations.

From an external perspective, actions by North Korea, China, the United States and Russia may provide obstacles to EU-Japan security relations. More specifically, a further worsening of the nuclear conflict with North Korea or an even more assertive maritime Chinese posture in the East China Sea would inevitably make Japan even more reliant on the US for its security. ${ }^{3}$

\footnotetext{
${ }^{3}$ In a recent special issue in International Affairs, Samuels and Wallace (2018) and Suzuki and Wallace (2018) consider Japanese strategic thinking in response to crises in north-east Asia. They envision Japan becoming less rather than more reliant on the US and instead enhancing its defensive capacity and broadening its alliance portfolio. Interestingly, the special issue does not consider the EU as a possible ally for Japan.
} 
Such developments would also likely undermine any efforts to strengthen EU-Japan security cooperation. In particular, an escalation of conflict between Japan and China would put pressure on the EU's so-called neutral stance position in the territorial dispute between China and Japan over the Senkaku/ Diaoyu islands. No doubt there would also be countermeasures by China to either ensure the maintenance of the EU's neutral stance or the priority of Sino-EU relations over EU-Japan security cooperation. Further, increased EU cooperation with China's Belt and Road Initiative (BRI) may sway EU preferences, and it would also affect its relationship with both Japan and the US and could cause potential conflict, especially with the US. Already differences exist between the US and the EU with regard to membership in the Asian Infrastructure and Investment Bank, which is the financial instrument of the BRI, in that while most EU states have become members, the US and Japan have refused to do so. Moreover, not only has the US sought to prevent European states from participating it also has started discussions with Japan, India and Australia to establish a rival joint regional infrastructure scheme to the BRI, which would support the current 'Free and Open Indo-Pacific' (FOIP) strategy, which was initiated by Japan in 2016. These discussions, in turn, have given rise to Chinese anxiety about the birth, or rebirth, of the 'Quad' as a polarizing alliance dedicated to China's containment, particularly in the South China Sea (Ujvari 2019:4). One consequence of such US/Japan counter-strategies could be rising Sino-US/Japan tensions which would pose challenges to EU attempts to maintain fruitful relations with all three partners. On the other hand, it is in the EU's interest to care about the FOIP, as the Indian Ocean is Europe's broader neighbourhood, linked to the EU via the Persian Gulf, and rhetorically, Japan's FOIP Strategy is in line with the 2016 EUGS in terms of its commitment to effective governance and the rule of law (Baldauff 2018).

In all these calculations, a crucial factor will be the prevailing security relationship Europe or NATO has with the United States. The Trump administration has emphasised that European members need to increase contributions to NATO to avoid jeopardising the US security commitment to Europe. Combined with a critical stance of the Trump administration versus the EU, these US actions weaken the role of the EU as a security provider in Asia. In a similar fashion, renewed Russian aggression in the Ukraine or other East European states may drag European attention and resources to localised engagement and might deter efforts to secure stability in Asia and/or give support to Japanese security.

Away from the traditional security areas of military and regional security, beneficial EU-Japan security developments are likely to arise in some of the non-traditional sectors of security. In part, this is promoted by President Trump's anti-global trade and multilateralism stance, which has direct bearings on the way the EU and Japan cooperate in the area of economic security. It is interesting in this context that while the EU and Japan complain about Chinese flouting of WTO rules, they are still prepared to join China in launching a case against the US at the WTO to stop it from justifying tariffs on steel and aluminium as security measures (Hanke 2018). The close alignment between EU and Japanese positions in response to geo-political developments was also apparent at the 26th EU-Japan Summit in 2019 (Henzenhorn 2019). 


\section{Conclusions}

Our main aim was to evaluate existing EU-Japan security cooperation and the prospects of future collaboration in light of the recently agreed SPA. Rather than treating EU-Japan security cooperation as a general phenomenon, a differentiated approach was used; the comparison across specific security sectors over three time periods spanning 1990 until 2017 introduced a dynamic element in the assessment of threat perception, policy convergence and security cooperation. In the initial analysis, levels of threat perceptions and convergence of policy responses were considered as main determinant for cooperation. However, it was also recognised that these opportunities for cooperation could either be promoted or impeded by intervening factors that are either internal or external to EU-Japan security relations. In other words, perceived threats and relevant policy responses can be deemed a necessary but not as sufficient explanation for determining cooperation.

Over the period 1991-2017, the EU as well as Japan faced an increasingly insecure environment. They perceived increased threat levels across a growing number of policy dimensions, but they did not necessarily agree on the main source of threats. During the same period, the EU and Japan have begun to share medium levels of convergence and cooperation across a majority of policy dimensions. At the same time, economic security cooperation remains the only dimension where the level of cooperation is high. Apart from economic security, the threat perception is higher than or matches levels of cooperation in all dimensions. There remains a demand (or opportunity) for cooperation in nearly all dimensions. Finally, the level of policy convergence also exceeds the level of cooperation in five dimensions - military security, regional security, terrorism, energy security and human security; in these dimensions, there remains therefore an unrealised potential for cooperation.

The SPA could be truly relevant. The limited impact from earlier bilateral EU-Japan initiatives - the Joint Declaration in 1991 and the Action Plan in 2001-resulted from some intrinsic drawbacks; for example, they were based on lofty security policy aims rather than clear priorities or targets. But possibly more significant, their limited impact also followed from the absence of a clear EU policy and institutional mechanisms in the field of security and defence, which really only kicked in with the implementation of the Lisbon Treaty in 2007-2009.

The SPA makes explicit references to more cooperation specifically in areas such as military and regional security, which have hitherto achieved mostly low levels of EU-Japan cooperation. Actions target greater collaboration in military industrial production and impeding proliferation via an effective system of export controls of dual-use and WMD-related good and technologies. The SPA should also facilitate collaboration to address human security concerns. As Vosse (2018: 231) argues: "In essence, the EU-Japan SPA is intended to intensify the way the EU and Japan cooperate in out-of-area security challenges". Further cooperative efforts are also foreseen in the non-traditional security fields such as on counterterrorism and organized crime, which have in the past received low levels of joint cooperation, and on economic security, civil protection, cyber-security and climate change, where already medium to high level of joint cooperation exists. Importantly, a Joint Committee has been established to ensure the proper functioning and the effective implementation of the Agreement. 
Regardless, a further worsening of relations between Japan and North Korea/China could complicate security cooperation with the EU. It will not only make Japan increasingly dependent on the US as the main external security provider but it could also force the EU to make a difficult choice in building relations with either China or Japan. Equally, renewed Russian aggression in the Ukraine or other East European states could divert European attention and resources away from its security cooperation with Japan. In short, geo-political developments combined with entrenched security ties to the United States could mean the EU and Japan continue to first of all see each other as 'a friend of a friend'.

At the same time, the SPA extends and institutionalises major bilateral engagements between the EU and Japan as 'old friends'. At a minimum, the regular meeting provide an opportunity for the EU and Japan to confirm their shared position versus global challenges; for example, at the leaders' video conference, the EU and Japan stressed the value of bi- and multilateral collaboration in dealing with the Covid-19 pandemic and reaffirmed their commitment to the SPA (European Council 2020). Possibly most significant, the SPA allows to EU and Japan to develop an agenda for further cooperation, and it has set a framework to establish collaboration in areas such as military procurement and cyber-security that promise to directly enhance security capacity of both the EU and Japan.

\section{References}

Akutsu H, Duke S (2019) EU-Japan military relations. In: Kirchner E, Dorussen H (eds) EU-Japan security cooperation. Routledge, London and New York, pp 37-55

Baldauff N (2018) Japan's free and open Indo-Pacific strategy: what does it mean for the EU? Egmont security policy brief no 100. Royal Institute for International Relations, Brussels

Bossong R, Bothe S (2019) The EU and Japan in the fight against terrorism and organized crime. In: Kirchner EJ, Dorussen H (eds) EU-Japan security cooperation. Routledge, London and New York, pp 74-92

Casarini N, Tsuruoka M (2019) Non-proliferation. In: Kirchner EJ, Dorussen H (eds) EU-Japan security cooperation. Routledge, London and New York, pp 56-73

de Prado Yepes C (2017) Toward a substantial EU-Japan partnership. Eur Foreign Aff Rev 22:435-454

Economist, the (2018) Japan and the United States: watching him nervously, 8 September, pp. 449-450

EUobserver (2020) EU and Japan in favour of WHO reform, 27 May 2020. Available at https://euobserver. com/tickers/148483?utm source=euobs\&utm medium=email. Accessed 11 June 2020

European Commission (2001) Europe and Asia: a strategic framework for enhanced partnerships

European Community (1991) Joint declaration on relations between the European Community and its member states and Japan. The Hague: http://eeas.europa.eu/japan/docs/joint_pol_decl_en.pdf

European Council (2003) European security strategy: a secure Europe in a better world. Brussels https://www. consilium.europa.eu/en/documents-publications/publications/european-security-strategy-secure-europebetter-world/

European Council (2012) Guidelines on the EU's foreign and security policy in East Asia: http://eeas.europa. eu/archives/docs/asia/docs/guidelines_eu_foreign_sec_pol_east_asia_en.pdf

European Council (2018) Deepening EU security cooperation with Asian partners: Council adopts conclusions: https://www.consilum.europa.eu/media/35379/st09265-en18.pdf

European Council (2020) Joint press release: Japan-EU leaders' meeting, Tuesday 26 May. Available at: https://www.consilium.europa.eu/en/press/press-releases/2020/05/26/joint-press-release-japan-eu-leadersmeeting/?utm_source $=$ dsms-auto\&utm_medium $=$ email\&utm_campaign $=J$ Joint + press + release $\% 3$ a+Japan-EU+Leaders\%27+meeting. Accessed 11 June 2020

European External Action Service (EEAS) (2019) The Partnership on Sustainable Connectivity and Quality Infrastructure between the European Union and Japan. Available at: https://eeas.europa. eu/headquarters/headquarters-homepage_en/68018/The $\% 20$ Partnership $\% 20$ on $\% 20$ Sustainable $\% 20$ 
Connectivity $\% 20$ and $\% 20$ Quality $\% 20$ Infrastructure $\% 20$ between $\% 20$ the $\% 20$ European $\% 20$ Union $\% 20$ and\%20Japan. Accessed 10 June 2020

European Union (2016) Shared vision, common action: a stronger Europe. A global strategy for the European Union's Foreign and Security Policy. www.eeas.europa.eu/archives/docs/top_stories/pdf/eugs_review_ web.pdf

Gale A, Tsuneoka C (2018) Japan unifies its Army command. The Wall Street Journal, Thursday 5 April

Geeraerts G (2019) Europe and China's Belt and Road Initiative: growing concerns, more Strategy. Egmont Security Policy Brief, No. 118

Gilson J (2016) The strategic partnership agreement between the EU and Japan: the pitfalls of path dependency. J Eur Integr 38:791-806

Hanke J (2018) EU and China break ultimate trade taboo to hit back at Trump. Politico, 21 November: https:/www.politico.eu/article/eu-and-china-break-ultimate-trade-taboo-to-hit-back-at-trump/

Henzenhorn D (2019) EU's best Western ally is now in the east. Politico, 26 April: https://www.politico. eu/article/eus-best-western-ally-is-now-in-the-east/

Kirchner, EJ, Dorussen H (eds) (2019) EU-Japan security cooperation. Trends and prospects. Routledge, London and New York

Kirchner EJ, Fanoulis E, Dorussen H, (2014) Civil security in the EU: national persistence versus EU ambitions?. Eur Secur 24(2):287-303

Most BA, Starr H (1989) Inquiry, logic, and international politics. University of South Carolina, Columbia

Russett B, Oneal JR (2001) Triangulating peace: democracy, interdependence and international organizations. W.W. Norton, New York

Samuels RJ, Wallace C (2018) Introduction: Japan's pivot in Asia. Int Aff 94:703-710

Suzuki S, Wallace C (2018) Explaining Japan's response to geopolitical vulnerabilities. Int Aff 94:711-734

Tsuruoka M (2008) "Expectation deficit" in EU-Japan relations: why EU-Japan partnership cannot flourish. Curr Polit Econ Asia 17:107-126

Tsuruoka M, Fiott D (2020) EU-Japan cooperation on defence capabilities: possibilities? Elcano Royal Institute, ARI 76/2020-22/5/2020. Available at: http://www.realinstitutoelcano.org/wps/portal/rielcano en/contenido?WCM_GLOBAL_CONTEXT=/elcano/elcano_in/zonas_in/ari76-2020-tsuruoka-fiott-eujapan-cooperation-on-defence-capabilities-possibilities

Ueta T (2013) The role of Europe in enhancing cooperative security in Asia and the Pacific: a view from Japan, Egmont security policy brief no. 50, Royal Institute for International Relations, Brussels

Ujvari B (2019) The Belt and Road Initiative- the ASEAN perspective, Egmont security policy brief no. 107, Royal Institute for International Relations, Brussels

Vosse W (2018) EU-Japan security partnership in practice: the counter-piracy mission off the coast of Somalia. In: Vosse W, Midford P (eds) Japan's new security partnerships. Manchester University Press, Manchester, pp 219-235

Publisher's note Springer Nature remains neutral with regard to jurisdictional claims in published maps and institutional affiliations. 